\title{
Investigating different patterns of student engagement with blended learning environments in Australian business education: Implications for design and practice
}

\author{
Graeme Pye \\ Deakin University \\ graeme.pye@deakin.edu.au
}

Dale Holt

Deakin University

Scott Salzman

Deakin University

\begin{abstract}
This research reports on a diverse student audience engaging in an Australian university's undergraduate commerce program core unit which was offered across three separate geographic campus locations and online. The research extends upon work undertaken on student engagement in online settings and lies in the domain of blended learning design and practice in the Australian higher education business context. The research adopted a dualperiod surveying approach aimed at comparing patterns of student engagement within a major business subject offered in two different trimesters in one academic year. The survey analysis compared student perceptions of engagement with the subject and identified significant variations in patterns of engagement based on key background and demographic factors. Findings, inter alia, are presented across seven major student engagement dimensions as applied to the interplay between online and located/campus learning (i.e. Online Active Learning, Online Social Interaction, Online Collaboration, Online Teaching, Online Assessment, Online Relevance, and Online Contact with Staff). Implications for blended learning design, eLearning and practice in such complex environments involving diverse student audiences are examined.
\end{abstract}

Keywords: Student engagement; blended learning; Australia; business education

\section{Introduction}

This research represents the initial findings of a multi-year project investigating student experiences of learning in contemporary blended learning environments in the field of business education. The project is based on developments in a large Faculty of Business and Law in an Australian university that operates across three campuses in three separate cities in metropolitan, regional and rural settings in the Australian State of Victoria. Australian and international universities continue to strategically seek competitive advantage by exploiting information and communication technologies (ICT) to service the needs of a diverse population of students, irrespective of their study location, through extending the options for flexible education, distance education, eLearning and blended learning.

The site of this research, Deakin University, has committed to the aspiration of pushing the digital frontier, with its accompanying 'Cloud' (online) and 'Located' (campus-based) learning vision. This vision is based on the University's historical commitment to distance and online education (for major educational technology developments within the institution see Challis, 
Holt, \& Rice, 2005; Holt \& Challis, 2007; Palmer \& Holt, 2014). The research project aims to enhance the quality of business education in Australian higher education by enlightening the powerful and dynamic interplay of student learning online and on location by: developing, piloting and refining a student engagement survey instrument related to Cloud and Located learning; ascertaining the nature and extent of student engagement in such blended learning environments; and developing a set of design principles and practices to enhance student engagement. The student engagement survey data collection is located within an educational design research orientation to advancing contemporary blended learning designs and practices through an iterative process of learning design principles interacting with practical interventions through evidence-driven approaches. The research focuses on ubiquitous Learning Management System (LMS) environments only and not the specific educational technology field of gaming and simulation spaces, including, for example, student engagement in virtual 3-D platforms like Second Life (see Holt, Segrave \& Cybulski, 2011).

This paper focuses on findings and implications from the summary results of a student engagement survey to students enrolled in two major offerings of a large, first year foundational disciplinary subject on business information systems offered in the Faculty's commerce program. The unit was offered on Location across three campuses and online via the Cloud. The survey is based on significant international work reported in the higher education literature relating to the key dimensions of student engagement in online learning environments. The subject had undergone significant change in response to the University's strategically directed Cloud and Located learning course enhancement processes. The research highlights both commonalties and differences in patterns of student engagement based on key demographic and background data. Gender, age and cultural differences are all highlighted. The findings contribute to the better balance of research undertaken on students as opposed to staff experiences of blended learning and teaching, along with foregrounding major design and practice implications.

\section{Background}

Various lines of conceptual framing have been developed to promote students learning online (Garrison \& Anderson, 2003; Bonk \& Zhang, 2008; Salmon, 2011). The current research aims to examine student perceptions of their experiences of evolving online and blended learning environments through the conceptual framing of student engagement. This research contributes to the large body of work on promoting student learning in online and blended learning settings in two important respects. First, it adds to the research undertaken on student experiences of blended learning and teaching. Second, the aim is to investigate students' views on how they are experiencing engagement, based on a strong line of higher education research in this field and to extend these investigations into the particular field of students engaging with contemporary blended learning environments. Student engagement focuses on the time and effort students put into purposively designed educational activities directed at achieving the desired learning outcomes (Coates \& McCormick, 2014). The student engagement enterprise synthesises significant bodies of knowledge on the student experience in higher education in key fields covering quality of effort (Pace, 1979; 1995), principles for good practice in undergraduate education (Chickering \& Gamson, 1987), student learning involvement principle (Astin, 1985) and student integration into university life and persistence in study (Tinto 1993; 1997). 
The phenomenon of student engagement has been well investigated and developed in the United States (Kuh, 2003; Kuh, Kinzie, Schuh, Whitt \& Associates, 2005). The student engagement enterprise and its empirically-driven approach as represented in the National Survey of Student Engagement (NSSE) originated in the US in the late 1990s and spread with major adaptations and applications in Canada, Australia and New Zealand, South Africa, China and Ireland (Coates \& McCormick, Eds., 2014) and the United Kingdom (Howson \& Buckley, 2017). While a powerful vehicle for illuminating the realities of the students' learning experience for quality assurance and improvement purposes, it has not been beyond critique in the Australian context (Hagel, Carr \& Devlin, 2012).

Drawing on the various bodies of knowledge and survey methodology relating to student engagement more generally, Coates (2006) investigated how learning technologies, as particularly prominent through the large-scale implementation of LMSs throughout higher education, were impacting campus-based student engagement. Citing Coates (2006, p.69), student surveys are structured conversations between learners and universities. Taking account of the more general set of dimensions constituting student engagement, Coates (2006) developed a set of student engagement constructs for online learning environments (as related to online learning engagement in campus-based located settings). Those used in this study cover:

- $\quad$ Online active learning: Key ways in which students use online systems to enhance learning;

- $\quad$ Online social interaction: Use of online learning systems to support general forms of social interaction;

- $\quad$ Online collaboration: Students' use of online systems to work collaboratively with peers;

- $\quad$ Online teaching: Whether teachers use online learning systems to promote effective learning;

- $\quad$ Online academic relevance: Use of online systems to enhance the relevance and context of study.

- $\quad$ Online contact with staff: Extent and ease of use of online systems by students in contacting staff.

This set of dimensions are directed at discovering what students self-report that they actually do online, as opposed to what teachers might think they should be doing. Coates' approach elicits student views on what and how much they have done of relevance to their academic pursuits. Not foregrounded explicitly in a separate construct by Coates (2006) was online assessment encompassing the various LMS features, functions and approaches which might enable stronger student engagement with assessment tasks and feedback in online and blended learning settings. The assessment features of LMSs are seen as potentially key benefits in supporting teaching and student learning online (Bennett, Dawson, Bearman, Molloy \& Boud, 2017), particularly relating to online assessment feedback (see Parkin, Hepplestone, Holden, Irwin \& Thorpe, 2012; Jonsson, 2014; Dawson, 2017). More generally, assessment review and redesign involving a major focus on more effective assessment feedback is seen as a compelling means of enhancing the student learning experience in higher education (Boud, 2010; Nicol, 2010; Boud \& Molloy, 2013; Henderson, Boud, Molloy, et al., 2016; Small \& Attree, 
2016; Winstone Nash, Rowntree \& Parker, 2017). Redesigning assessment has been a key activity in reviewing and renewing curriculum design and delivery in Australian higher education, as advanced by senior university educational leadership (see Oliver, 2013; Lawson, 2015). A discrete construct relating to online assessment was seen as an important addition to those drawn from Coates' (2006) work.

These constructs of online student learning inform the development of a student engagement survey for Cloud and Located learning in this research relating to a business education context. As reported by Pye, Holt, Salzman, Bellucci and Lombardi (2015), certain statistically significant differences were detected within and across the online student engagement constructs in the first offering of the business information systems subject as related to key background and demographic factors, i.e. gender, age, mode of enrolment, culture. This research further investigates the existence of such differences. Coates (2006, p.11) set aside the investigation of differences in patterns of student engagement, and a focus on whether or not such differences exist, and the reasons why this might be the case. This research is an important extension of his work, particularly relating to potential differences in student engagement based on key background and demographic factors like culture and gender.

Culture and Gender are major areas of study in higher education. Culture has figured prominently given the substantial number of international students who study in Australia, particularly those drawn from Asia, and China specifically. Cultural differences have been illuminated relating to Chinese Confucian and pedagogical traditions and practices, and their intersections with Western higher education approaches (Choi \& Nieminen, 2013). These concerns have been extended into cultural factors pertaining to online learning (Chen, Bennett \& Maton, 2008; Chen, Hsu \& Caropreso, 2006; Liu, Liu, Lee \& Magjuka, 2010). Liu et al. (2010, p.179), citing Zhang (2007), observe that:

"Numerous studies that have examined the cultural differences between Western and Eastern education have provided a consistent picture that describes Eastern education as a group-based, teacher-dominated, centrally organized pedagogical culture with examinations as the essential way to define performance and compete for higher social status."

Often cited is the seminal work of Hofstede (2001) and his identification of different dimensions of culture, namely; Power Distance (the degree of acceptance of unequal power relationships); Individual-Collectivism; Uncertainty Avoidance; and Masculinity-Femininity. While not without its critics, it is a helpful way of framing possible explanations of differences in patterns of international/domestic student engagement online reported in this study.

Gender factors have also received attention in relation to engagement with the Internet in general, particularly ICT educational research. Gender differences relating to levels of online anxiety, self-efficacy in teaching using computers (Wong, Teo \& Russo, 2012; Teo, Fan \& Du, 2015), learning styles in the computer sciences (Lau \& Yuen, 2010), ICT literacy (Markauskaite, 2006) and power inequalities, conflict and harassment (Li, 2005) have, for example, been reported. Gender role orientations to interacting with the Internet have been examined from a broader social psychological perspective (Wallace, 1999) and highlights how unhelpful gender stereotypes can play out online. Closer to this study is work reported on gender issues in online learning (McSporran \& Young, 2001; Gunn, French, McLeod, McSporran \& Conole, 2002). These studies present often conflicting evidence around gender (in)equality online, and whether, in fact, in-person, face-to-face gender power inequalities are just socially 
reconstructed online. However, their main finding is that inclusive, universal design of online learning environments is the best way forward to ensuring fair and reasonable treatment and positive learning for all categories of students. Gender in this study is investigated in the context of student engagement with blended learning, and represents a somewhat different perspective. A study of closer relevance to this investigation is that by Tsai, Liang, Hou \& Tsai (2015). This work is returned to later in this paper when findings are discussed and implications examined.

\section{Research methodology}

This investigation is situated within the realm of educational technology research relating to design-based research. This domain of research activity develops and receives considerable attention in international educational technology communities (Kopcha, Schmidt \& McKenney, 2015; Reeves, 2015). McKenney and Reeves (2012, p.7) define educational designbased research:

“...as a genre of research in which the iterative development of solutions to practical and complex educational problems also provides the context for empirical investigation, which yields theoretical understanding that can inform the work of others."

The business subjects researched as part of this overall study, including the one which is the focus of this paper, have all undergone major course enhancement as part of the University's commitment to review and renewal of its courses. Course enhancement has covered all aspects of curriculum design, delivery and assessment. Units surveyed continue to review and refine their blended learning design approaches as stimulated by the University's course transformation agenda. Informed by contemporary developments in graduate attribute development, authentic assessment and Cloud/Located learning, student engagement research is seen as a major means of evaluating student learning experiences to date, and to help inform further development of the blended learning designs in action. The twin pillars of student engagement and design-based research form a robust methodology for advancing theory and practice.

\subsection{Key research questions for informing design and practice}

Analysis of the literature on student engagement, online student engagement and the demographic and background factors identified as potentially shaping patterns and variations in online student engagement, led to the formulation of two major research questions and four associated hypotheses which form the basis of survey analysis and interpretation. The survey instrument was designed to include the key dimensions of student engagement, and to allow commonalities and differences in patterns of student engagement to be analysed by the key background and demographic factors. The importance of the differences was considerably highlighted in the actual undertaking of the analytical work with the data set, and so the investigation has been partly grounded in nature with lines of research inquiry being responsive to the actual results of the data analysis.

The research questions and hypotheses are:

- $\quad$ RQ1: Were there any significant differences in the ways responding students engaged with the subject over different trimester period offerings? At face value, it was not expected to find significant differences given the subject design and 
delivery was essentially unchanged for both offerings, unless significant differences were identified in the actual student cohorts undertaking the subject in the different teaching periods.

- $\quad$ RQ2: In analysing student engagement data over the two subject offerings, did any significant differences emerge in student engagement based on key demographic and background factors?

- $\quad$ Hypothesis 1: Responding males and females should rank similarly with respect to their overall level of agreement with each of the different construct themes AND each of the items associated with each theme.

- $\quad$ Hypothesis 2: Both Located (on-campus) and Cloud (off-campus) participating students should rank similarly with respect to their overall level of agreement with each of the different construct themes AND each of the items associated with each theme.

- $\quad$ Hypothesis 3: Both domestic and international responding students should rank their overall level of agreement with each of the different construct themes similarly AND each of the items associated with each theme.

- $\quad$ Hypothesis 4: Students of different age groups who responded should rank their overall agreement with each of the different construct themes similarly AND each of the items associated with each theme.

Finally, if significant differences can be identified, what implications would such findings have for designing and practicing within such blended learning environments?

\subsection{Online student engagement survey design}

This research uses a survey design to ascertain student views on how, and how much, they are engaging with their collective Cloud and Located learning environments. The online survey method utilised gave the most number of students the best opportunity to share their views on what they have each personally experienced. Drawing on an already developed, trialled and validated student engagement survey related to online learning by Coates (2006) outlined above, the survey developed for this research is relevant to the experiences to be elicited, and efficient to administer with large student cohorts.

The student engagement survey used the six key constructs identified by Coates (2006) and associated activities. A seventh student engagement dimension was added relating to various activities associated with online Assessment. In addition to the seven constructs of student engagement (see Appendix), several other pertinent factors were surveyed as summarised in Table 1. 


\section{Other survey factors:}

- Background information: gender, primary campus of study, age, student status (domestic or international);

- $\quad$ Accessing and downloading learning resources to mobile devices;

- Use of social media for social/collaborative purposes;

- $\quad$ Effectiveness of integration of Cloud (online) and Located (campus) environments (on-campus students only);

- $\quad$ Amount of time studying unit on average per week;

- $\quad$ Achievement of unit learning outcomes;

- $\quad$ Amount of time spent studying unit online;

- $\quad$ Amount of study time spent studying unit away from campus (on-campus students only);

- $\quad$ Learning benefits of online environment;

- $\quad$ Most and least effective aspects of unit blended learning environment.

Table 1: Other survey factors

Questions relating to use of social media for social/collaborative purposes, and most and least effective aspects of the subject's blended learning environment were open-ended. Given space constraints, the qualitative analysis of the large number of responses to these items is not within the scope of this paper.

\subsection{Data collection and response rate}

The Commerce program core unit, Business Information Systems was surveyed in Trimester 1 and 2, 2014, using the University's online surveying tool, Opinio.

In Trimester 1, the number of Opinio Invitee emails was 1348. Minus the three survey administrations parties (two team members \& SIS group), the total number of student invitees was 1345 . The self-selected sample was collected with a response rate of $10.26 \%$ for Trimester $1,2014(\mathrm{n}=138)$ :

\begin{tabular}{|l|l|l|l|l|}
\hline & \multicolumn{1}{|c|}{ Population } & \multicolumn{1}{|c|}{ Sample } & $\begin{array}{c}\text { Response Rates } \\
(\mathbf{1 3 4 5 )}\end{array}$ & $\begin{array}{c}\text { Response Rates } \\
\text { (138) }\end{array}$ \\
\hline Invitees (Totals): & 1345 & 138 & $10.26 \%$ & \\
\hline \multicolumn{5}{|l|}{} \\
\hline $\begin{array}{l}\text { Invitees (Survey } \\
\text { Completions): }\end{array}$ & 1345 & 104 & $7.73 \%$ & $75.36 \%$ \\
\hline $\begin{array}{l}\text { Invitees (Survey } \\
\text { Incompletes): }\end{array}$ & 1345 & 34 & $2.53 \%$ & 24.63 \\
\hline Total: & & 138 & $10.26 \%$ & $99.99 \%$ \\
\hline
\end{tabular}

Table 2: Trimester One, 2014 response rates

Comparisons between sample and population demographic and background factors for the Trimester 1 offering of the subject were: 


\begin{tabular}{|c|c|c|}
\hline & \multicolumn{2}{|c|}{ Students } \\
\hline & Sample & Population \\
\hline No. of respondents & 104 & 1345 \\
\hline $\begin{array}{l}\text { Response rate } \\
\text { (completions) }\end{array}$ & $7.73 \%$ & - \\
\hline \multicolumn{3}{|l|}{ Gender } \\
\hline Female & $44(42 \%)$ & $503(38 \%)$ \\
\hline Male & $60(58 \%)$ & $842(62 \%)$ \\
\hline \multicolumn{3}{|l|}{ Mode of enrolment } \\
\hline Located/on-campus & $83(80 \%)$ & $1194(89 \%)$ \\
\hline Cloud/online/off-campus & $21(20 \%)$ & $151(11 \%)$ \\
\hline \multicolumn{3}{|l|}{ Campus } \\
\hline Melbourne Burwood & $60(58 \%)$ & $898(67 \%)$ \\
\hline Geelong Waterfront & $15(14 \%)$ & $254(19 \%)$ \\
\hline Warrnambool & $8(8 \%)$ & $42(3 \%)$ \\
\hline Cloud/online/off-campus & $21(20 \%)$ & $151(11 \%)$ \\
\hline \multicolumn{3}{|l|}{ Domestic/International } \\
\hline Domestic & $95(91 \%)$ & $1218(91 \%)$ \\
\hline International & $9(9 \%)$ & $127(9 \%)$ \\
\hline \multicolumn{3}{|l|}{ Age } \\
\hline $18-21$ & $71(68 \%)$ & $1001(74 \%)$ \\
\hline $22-25$ & $8(8 \%)$ & $223(17 \%)$ \\
\hline $26-30$ & $6(6 \%)$ & $54(4 \%)$ \\
\hline $31-36$ & $12(11 \%)$ & $41(3 \%)$ \\
\hline $37-42$ & $1(1 \%)$ & $13(1 \%)$ \\
\hline Above 42 & $6(6 \%)$ & $13(1 \%)$ \\
\hline
\end{tabular}

Table 3: Trimester One, 2014 comparison between sample and population demographics

In Trimester 2, for the subject, the number of Opinio Invitee emails was 516. Minus the two survey administrations parties (two team members), the total number of student invitees was 514.

The self-selected sample was collected with a response rate of $8.17 \%$ for Trimester 2,2014 ( $n=$ 42):

\begin{tabular}{|l|c|c|c|c|}
\hline & Population & Sample & $\begin{array}{c}\text { Response Rates } \\
\mathbf{( 5 1 4 )}\end{array}$ & $\begin{array}{c}\text { Response Rates } \\
\text { (42) }\end{array}$ \\
\hline Invitees (Totals): & 514 & 42 & $8.17 \%$ & \\
\hline \multicolumn{5}{|l|}{} \\
\hline $\begin{array}{l}\text { Invitees (Survey } \\
\text { Completions): }\end{array}$ & 514 & 35 & $6.81 \%$ & $83.33 \%$ \\
\hline $\begin{array}{l}\text { Invitees (Survey } \\
\text { Incompletes): }\end{array}$ & 514 & 7 & $1.36 \%$ & $16.67 \%$ \\
\hline Total: & & 42 & $8.17 \%$ & $100 \%$ \\
\hline
\end{tabular}

Table 4: Trimester Two, 2014 response rate

Comparisons between sample and population demographic and background factors: 


\begin{tabular}{|c|c|c|}
\hline & \multicolumn{2}{|r|}{ Students } \\
\hline & Sample & Population \\
\hline No. of respondents & 42 & 514 \\
\hline $\begin{array}{ll}\text { Response } & \text { rate } \\
\text { (completions) } & \end{array}$ & $8.17 \%$ & - \\
\hline \multicolumn{3}{|l|}{ Gender } \\
\hline Female & $17(40 \%)$ & $265(52 \%)$ \\
\hline Male & $25(60 \%)$ & $249(48 \%)$ \\
\hline \multicolumn{3}{|l|}{ Mode of enrolment } \\
\hline Located/on-campus & $27(64 \%)$ & $396(77 \%)$ \\
\hline Cloud/online/off-campus & $15(36 \%)$ & $118(23 \%)$ \\
\hline \multicolumn{3}{|l|}{ Campus } \\
\hline Melbourne Burwood & $26(62 \%)$ & $396(77 \%)$ \\
\hline Geelong Waterfront & $1(2 \%)$ & - \\
\hline Warrnambool & - & - \\
\hline Cloud/online/off-campus & $15(36 \%)$ & $118(23 \%)$ \\
\hline \multicolumn{3}{|l|}{ Domestic/International } \\
\hline Domestic & $30(71 \%)$ & $338(66 \%)$ \\
\hline International & $12(29 \%)$ & $176(34 \%)$ \\
\hline \multicolumn{3}{|l|}{ Age } \\
\hline $18-21$ & $21(50 \%)$ & $233(45 \%)$ \\
\hline $22-25$ & $9(21 \%)$ & $175(34 \%)$ \\
\hline $26-30$ & $6(14 \%)$ & $64(12 \%)$ \\
\hline $31-36$ & $3(7 \%)$ & $19(4 \%)$ \\
\hline $37-42$ & $2(5 \%)$ & $16(3 \%)$ \\
\hline Above 42 & $1(3 \%)$ & $7(2 \%)$ \\
\hline
\end{tabular}

Table 5: Trimester Two, 2014 comparison between sample and population demographics

The survey system saves responses after each page is completed, so some partially completed responses exist. In the following sections, the maximum applicable number of useful responses is used, and that number indicated.

\section{Data analysis and findings}

All data was managed using Microsoft XL 2013 and analysed using XL Statistics Version: 09.09.24. It is noted the inherent bias often present in self-selecting, online surveys implies that it is possible that some groups might be disproportionately represented. Conclusions therefore relate to self-reported levels of agreement. All error considered is representative of a 95\% confidence interval and all hypotheses tests use critical alpha set at 5\%. The Pearson's Chisquare test was used to test if two sets of categorical data were independent. To assess for differences between two Means, the t-test was used. Testing for a difference between more than two means required the use of the one way analysis of variance test and where necessary, post hoc tests were assessed using a t-test. No corrections were made for possible family-wise error. Where assumptions required for any statistical analysis could not be met, summary statistics only are presented. To allow for simpler explanations, some data was recoded.

Deakin University's LMS is branded 'CloudDeakin'. All references to CloudDeakin below are to the University's LMS and its various features, functions and uses. 
Research Question 1: Were there any significant differences in the ways students engaged with the subject over different period offerings?

Differences in composition of cohorts

Only two major differences in the comparison of the cohorts were identified in the two trimester subject offerings. Trimester 2 responses had a significantly higher proportion of international students and significantly less domestic students. With respect to internationals students, they represented $29 \%$ of the responding student cohort in Trimester 2 compared to $9 \%$ in Trimester 1 . This was an increase of $20 \%$. With respect to domestic students, they represented $91 \%$ of the cohort in Trimester 1, yet only $71 \%$ in Trimester 2. A proportional decrease of $20 \%$ (Chi-square 9.638, DF 1, p-value $=0.002$ ).

Regarding the percentage of first, second and third year students studying the subject in each Trimester ( 1 \& 2) of 2014, a statistically significant difference was evident (Chi-square 6.593, DF 2, p-value $=0.037$ ). The percentage of first year students participating in the second Trimester of 2014 reduced from $84 \%$ to $64 \%$, and alternatively, the percentage of second year students participating in Trimester 2 was greater than it was in Trimester 1, rising from 13\% to $25 \%$. That is, it appears that Trimester 2, 2014 had a larger proportion of comparatively academically mature students.

Differences in student engagement

No differences were detected between responding students from both Trimester 1 and Trimester 2, 2014 regarding the amount of time that they indicate they are studying online through the LMS.

With respect to how well students think they will achieve as a function of how much study they indicate that they did, students from both Trimester 1 and Trimester 2, 2014 do not have significantly different opinions. That is, regardless of the amount of study that students indicate that they do each week, only $4.6 \%$ of responding students think that they have achieved all of the required learning outcomes.

Results consistent with Trimester 1 subject offering were:

- $\quad 75.9 \%$ of all responding students indicated that Cloud learning and Located classroom learning were modes of education that were both relevant, and enhanced each other.

- $\quad 56.6 \%$ of all respondents at least agreed that Cloud learning maximised their learning from on campus classes.

- $\quad 75.7 \%$ of all respondents at least agreed that Cloud learning allowed them to organise their study time more effectively around their work and their personal commitments and,

- $81.6 \%$ of all respondents at least agreed that Cloud learning allowed them to learn the subject materials more conveniently.

Overall, with the exception of assessment (t 2.078, DF 578, p-value -0.038) with responding students indicating slightly, yet a significantly greater level of agreement in Trimester 2, 2014 compared to Trimester 1 (a mean in T2 of 4.1 compared to a mean of 3.9 in T1), there was no change witnessed in the way that students responded to the different items of the themed constructs between Trimester 1 and Trimester 2 of 2014 . 
Research Question 2: In analysing student engagement data over the two subject offerings, did any significant differences emerge in student engagement based on key demographic and background factors?

Hypothesis 1: Responding males and females should rank similarly with respect to their overall level of agreement with each of the different construct themes AND each of the items associated with each theme.

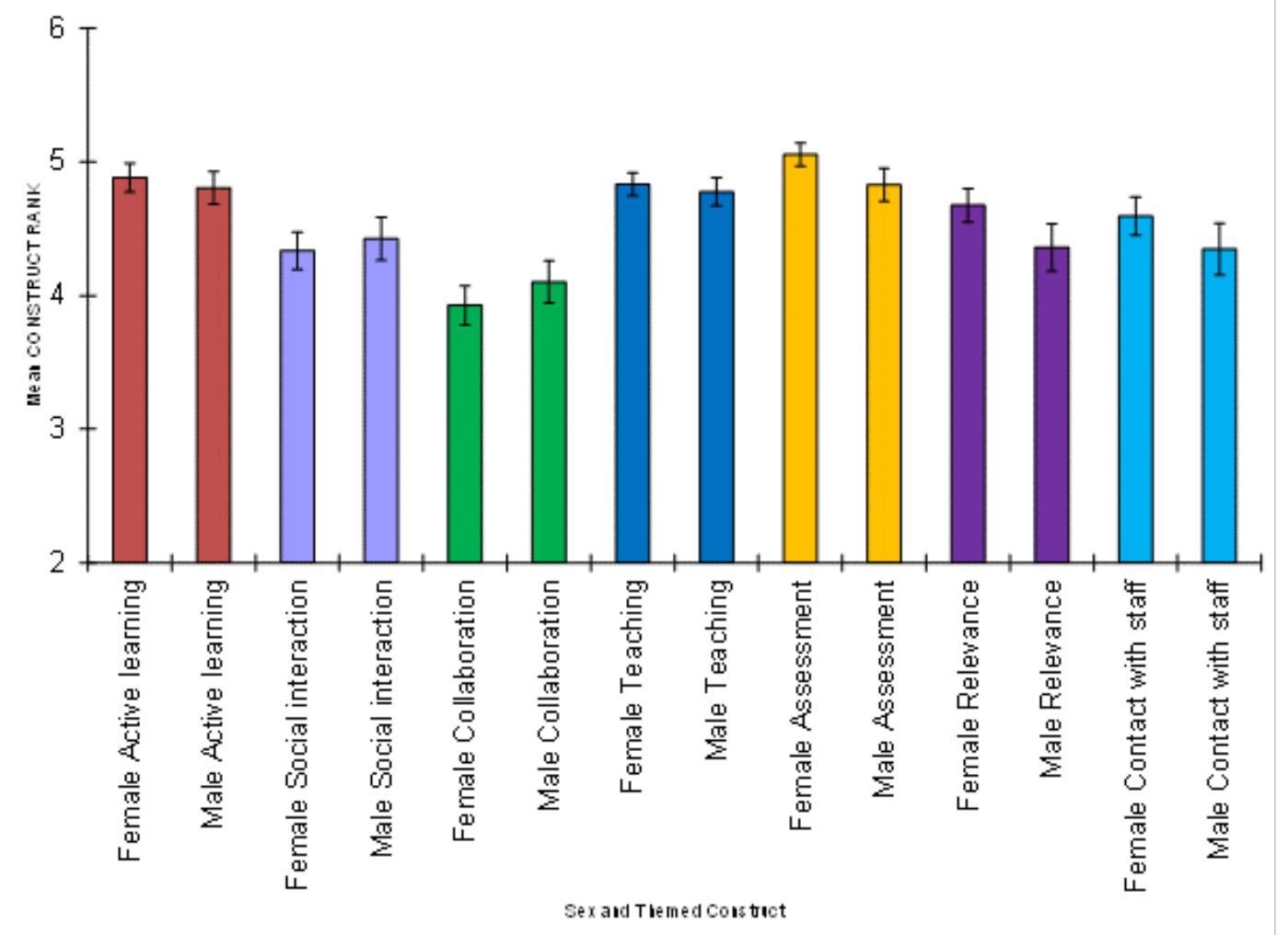

Figure 1: Mean score for each of the hypothesised latent constructs as a function of gender

Regarding the statements themed around "Assessment": 1 . Assignments were easy to locate online; 2 . Tests were easy to locate online; 3 . Assignments were easy to submit online; 4 . Online assignment submission gave me more time to complete assessable work; 5 . Online assignment feedback helped me improve my understanding of the topic, and; 6. Online assignment feedback helped me prepare for subsequent assessable work. Responding females are more inclined to be in agreement with these statements when compared to responding males $(\mathrm{t}$ 2.950, DF 669, p-value $=0.003$ ). Both genders however, are at least, in agreement with the statements regarding "Assessment".

Regarding the statements themed around "Relevance": 1. Using CloudDeakin made my study seem more relevant; 2. Using CloudDeakin made me feel part of the University, and; 3. Using online materials helped me put my study in real-world contexts. Responding females are more inclined to be in agreement with these statements when compared to responding males $(\mathrm{t}$ $2.859, \mathrm{DF} 360, \mathrm{p}$-value $=0.004)$. It is noted that both genders are at least, in agreement with the statements regarding "Relevance".

Regarding the statements themed around "Contact with staff": 1. I used CloudDeakin to contact academic staff; 2. I found it easy to communicate with staff online, and; 3. I had individual contact with academic staff online. Responding females are more inclined to be in agreement with these statements when compared to responding males (t 2.022, DF 321, p- 
value $=0.044)$. Both genders are however, at least in agreement with the statements regarding "Contact with staff".

Overall, these detected differences were unexpected.

Hypothesis 2: Both Located (on-campus) and Cloud (off-campus) participating students should rank similarly with respect to their overall level of agreement with each of the different construct themes AND each of the items associated with each theme.

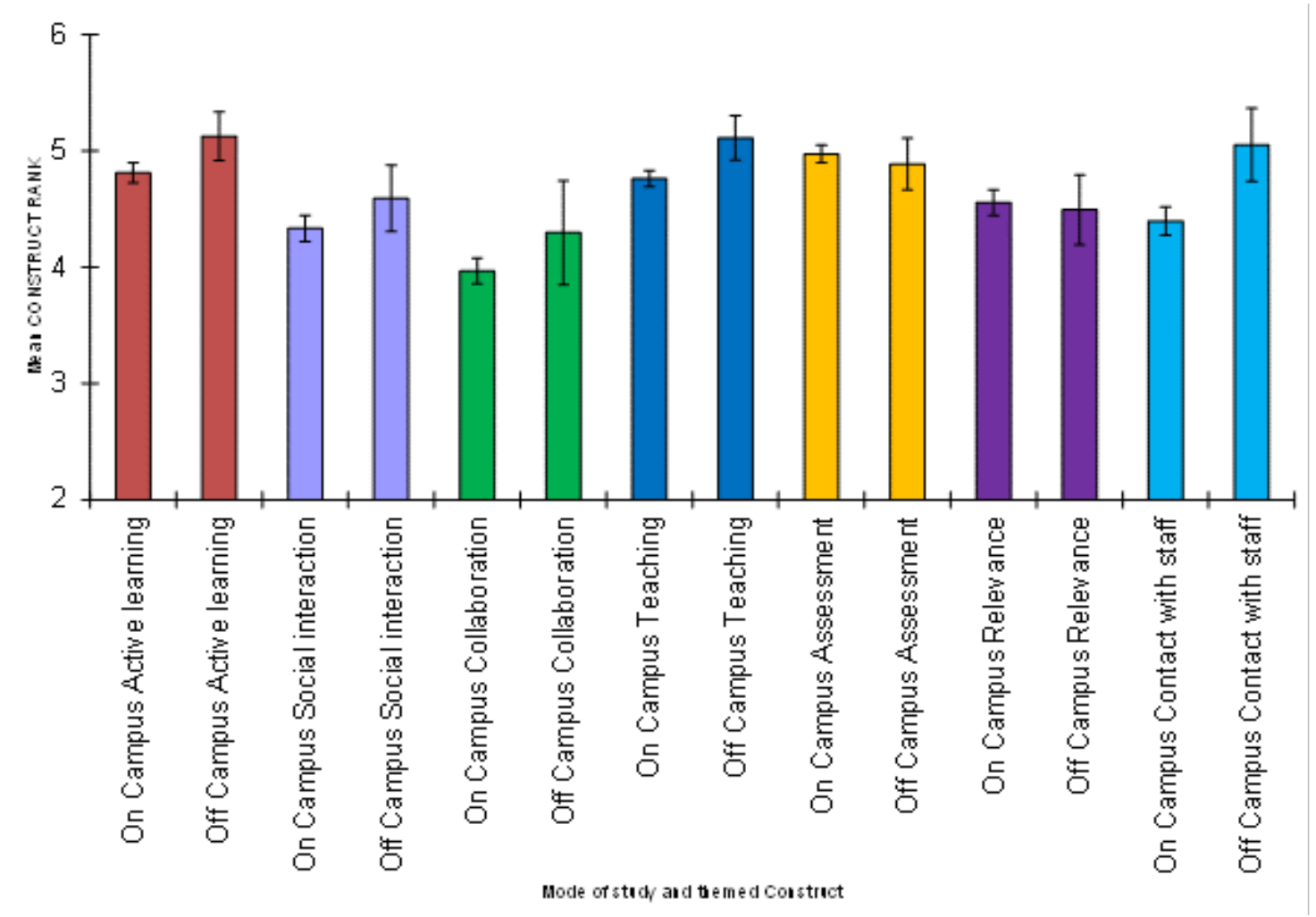

Figure 2: Mean score for each of the hypothesised latent constructs as a function of studying in an on or off campus mode

A significant difference is evident between responding Located (on-campus) and Cloud (offcampus) students with respect to the statements made around the theme "Active Learning" $(\mathrm{t}$ -2.786, DF 108, p-value $=0.006$ ). Although both Located and Cloud students are generally in "Agreement" with the statements made regarding "Active Learning" (1. I used online materials to improve my learning; 2. I used online materials to make Classroom learning more meaningful; 3. I identified expected academic standards using the CloudDeakin unit site, and; 4. I found that online materials challenged me to learn), Cloud students are more inclined to be in agreement with these statements compared to Located students. Compared to Located students, responding Cloud students appear to have less difficulty finding and using resources.

A significant difference is evident between responding Located and Cloud students with respect to their level of agreement with the statements made around the theme "Teaching" $(\mathrm{t}$ -3.455, DF 158, p-value $=0.001$ ). Although both Located and Cloud students are generally in "Agreement" with the statements made regarding "Teaching" (1. Teaching staff participated in online discussion; 2. I found it easy to explain my ideas in online discussions; 3. I had helpful online discussions with other students, and; 4 . I met new people when using the CloudDeakin 
system), responding Cloud students are more inclined to be in agreement with these statements compared to Located students and Cloud students appear to have also found the LMS discussion forums related to teaching more helpful.

A significant difference is evident between responding Located and Cloud students with respect to their level of agreement with statements made around the theme "Contact with staff" ( $t-2.670$, DF 114, p-value = 0.009). Regarding the statements made about "Contact with staff" (1. I used CloudDeakin to contact academic staff; 2. I found it easy to communicate with staff online, and; 3 . I had individual contact with academic staff online), responding Cloud students are more inclined to be in agreement with these statements compared to Located students, Cloud students knew where and how to contact fellow students and staff.

Hypothesis 3: Both domestic and international responding students should rank their overall level of agreement with each of the different construct themes similarly AND each of the items associated with each theme.

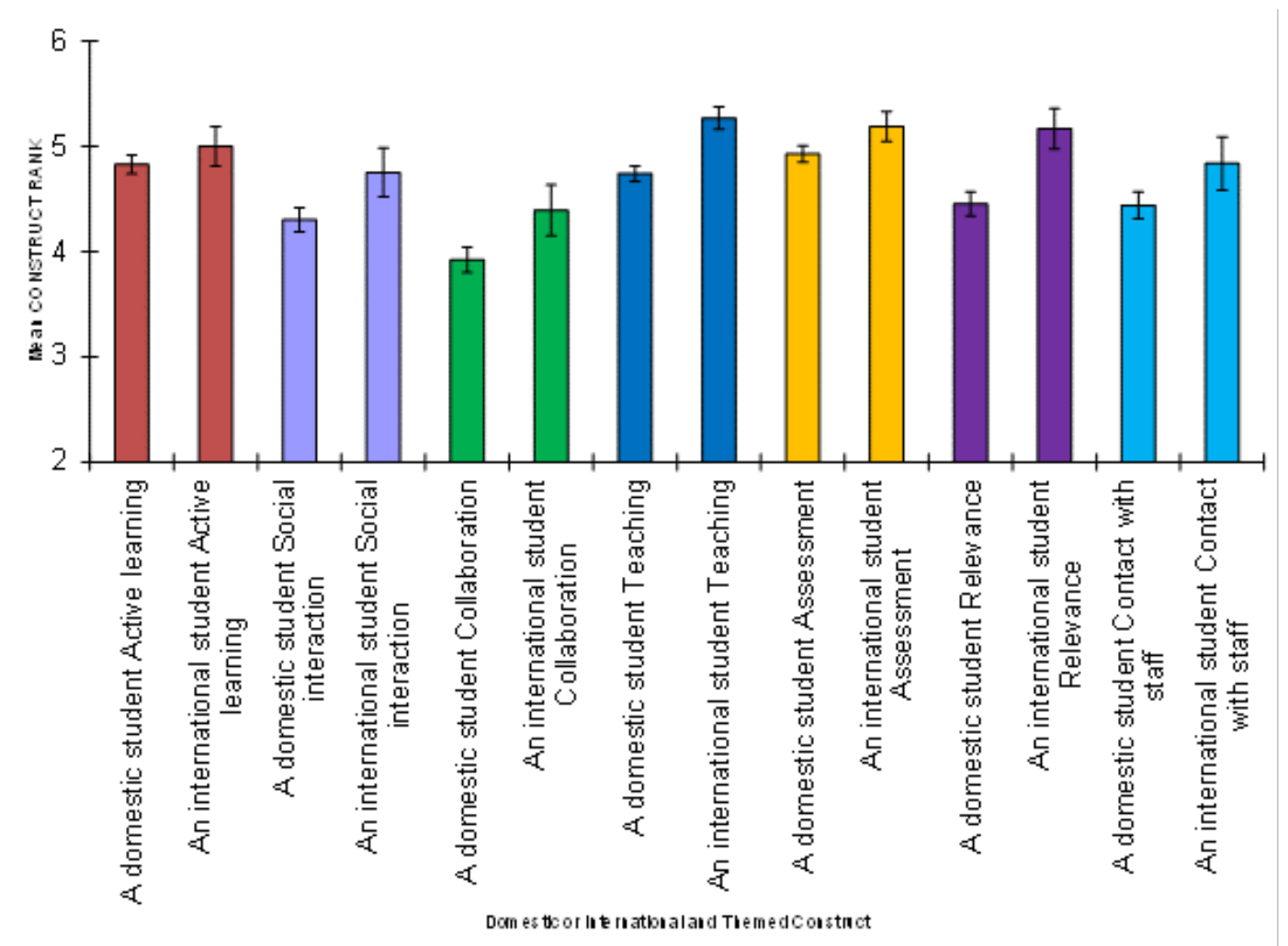

Figure 3: Mean score for each of the hypothesised latent constructs as a function of being an international or a domestic student

With the exception of "Active Learning", when comparing responding international and domestic students, all themed constructs revealed a significant difference: Social interaction $(\mathrm{t}$ -3.463, DF 124, p-value = 0.001); Collaboration ( $\mathrm{t}-3.481$, DF 119, $\mathrm{p}$-value $=0.001)$; Teaching $(\mathrm{t}-$ 8.045, DF 244, p-value < 0.00000) very highly significant; Assessment ( $\mathrm{t}-3.167$, DF 198, p-value $=0.002)$; Relevance $(\mathrm{t}-6.396, \mathrm{DF} 108, \mathrm{p}$-value < 0.00000) very highly significant; and Contact with staff $(t-2.799$, DF 85, p-value $=0.006)$. With the exception of "Active Learning", when compared to responding domestic students, responding international students were significantly more likely to be in agreement with all of the statements considered. 
Hypothesis 4: Students of different age groups who responded should rank their overall agreement with each of the different construct themes similarly AND each of the items associated with each theme.

Age data was recoded into two groups: 25 years old or less, and those over 35.

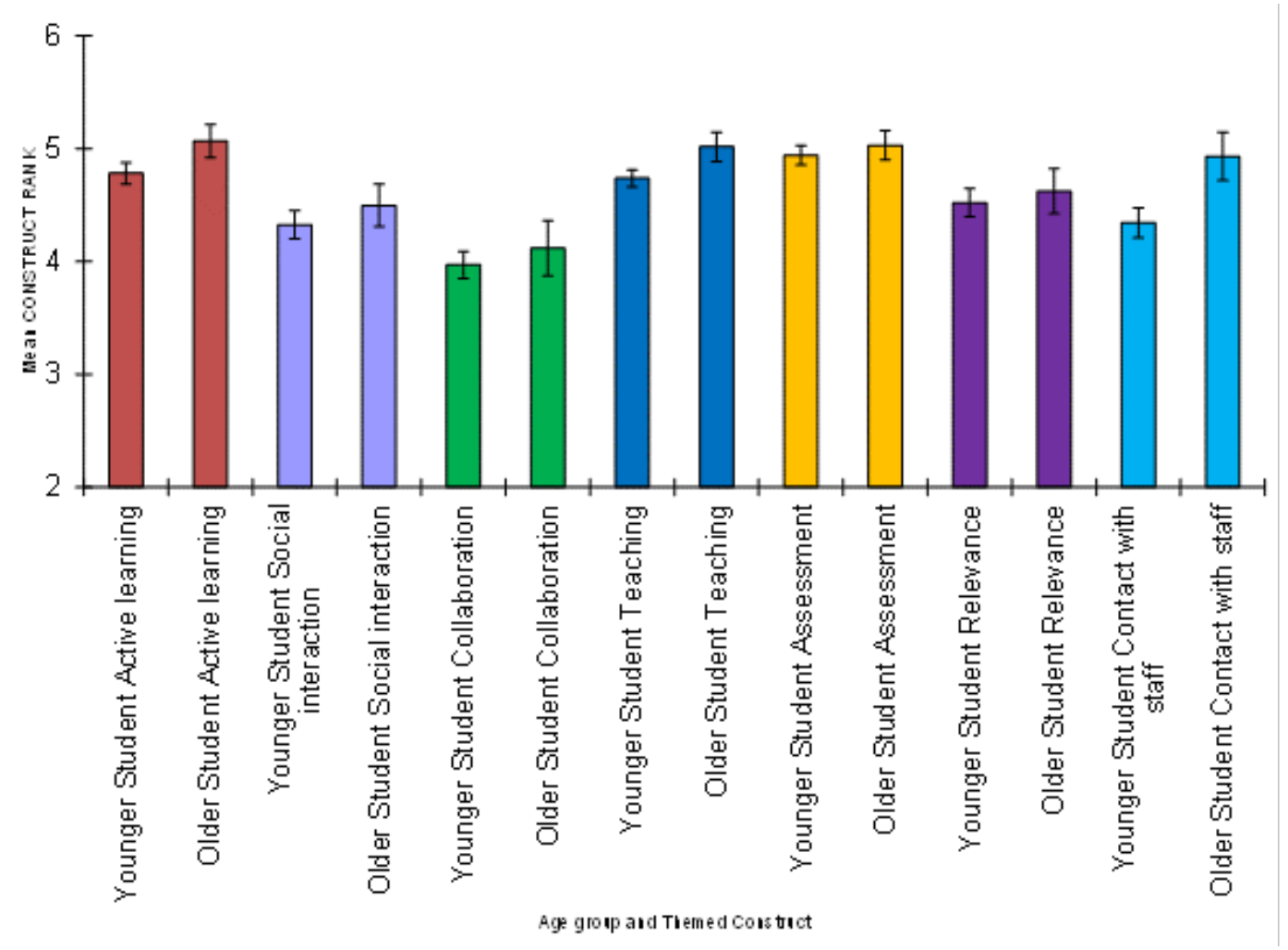

Figure 4: Mean score for each of the hypothesised latent constructs as a function of being a younger (25 years or less) or an older student (older than 25 years)

Differences in the responding students age groups across the constructs can be identified for: Active learning ( $\mathrm{t}-3.211$, DF 293, p-value $=0.001)$; Teaching $(\mathrm{t}-3.687$, DF 410, $\mathrm{p}$-value $<0.000)$ were highly significant; and Contact with Staff $(\mathrm{t}-4.642$, DF 187, p-value $<0.00000)$ very highly significant. For each of these three construct themes (Active learning, Teaching and Contact with Staff), when compared to respondents who are less than 26 years of age, responding students who are 26 years or older are more likely to agree with statements made regarding these overarching themes.

- $\quad$ Active learning: I used online materials to improve my learning; I used online materials to make Classroom learning more meaningful; I identified expected academic standards using the CloudDeakin unit site;

- $\quad$ Teaching: I found that online materials challenged me to learn Staff used CloudDeakin to clarify what was required to do well; Staff used CloudDeakin in ways that improved the overall teaching; Academic staff made an effort to communicate with students online; Academic staff used CloudDeakin to provide students with extra assistance; Teaching staff used CloudDeakin to tailor activities for students; and Teaching staff used CloudDeakin to discuss interesting issues, and;

- $\quad$ Contact with staff: I used CloudDeakin to contact academic staff; I found it easy to communicate with staff online; I had individual contact with academic staff online. 
That is, "older students" (> 25 years) appear to appreciate the resource, or perhaps get more out of using the resource, when compared to younger students ( 25 years old or less).

\section{Discussion of findings for design and practice}

The comparative study of the same subject offered in two different trimesters did not yield any major significant differences in student engagement, with the exception of Assessment. This may be explained by the fact that a fault in the online assessment rubric existed in the first offering, but was rectified in the second offering. Therefore, assessment was seen to be easier in the second compared to the first offering of the subject. No significant difference between offerings was largely expected as the subject's curriculum, assessment and online environment was unchanged. The only significant change was the Trimester 2, 2014 offering was Located on one campus and the Cloud rather than across the three campuses including the Cloud as in the Trimester 1, 2014 offering. The smaller and possibly less diverse student group was a factor, but limited in impact overall. However, the research has identified some significant differences in self-reported agreement with different online student engagement constructs with the completion of the two-offering comparative analysis.

First, the differences between international and domestic student views is significant across all constructs with the exception of Active Learning. A caveat is in order. Clearly, the domestic student cohort might represent significant cultural diversity, which has not been delineated in this work. Similarly, international students might come from a range of cultural backgrounds, although it can be assumed that they are primarily from Asian countries. These important cultural nuances potentially within cohorts must be acknowledged. However, the detected differences are worthy of recognition and exploration. Cultural differences are usually assumed in cross-cultural communication behaviours in online learning environments (Chen, et al. 2006), with the challenge usually being to include students from other cultures centrally into the planned learning experience. This study highlights the special perceived value that international students attribute to the functions and features of a mainstream online learning system, centring on an LMS. It can be seen that comparatively, international students particularly like the highly structured and regulated nature of the environment for facilitating their learning. The teacher's role as the clearly defined authority for orchestrating resources, monitoring and steering discussions, answering questions, and setting up devices like online assessment rubrics for detailed and structured assessment feedback, is strongly evident. One could suggest this student cohort feels particularly comfortable, safe and productive in such instructivist-oriented online and blended learning environments. It is a cautionary finding, yet fortified by Hofstede's (2001) cultural dimensions relating certain group's behaviours in accepting power differentials in the student-teacher relationship online, and in demonstrating behaviours embracing of certainty in the formulation of design expectations and associated practices. More authentic, constructivist environments may generate unique and exciting learning benefits, but they may be particularly confronting to student cohorts from different cultural and by implication, educational backgrounds.

Second, gender differences were identified, with females indicating overall higher perceived levels of online engagement across all constructs, with significant differences in the dimensions of assessment, relevance and contact with staff. One can only speculate as to whether and why females might be more attentive to assessment online, perhaps more so seeing the relevance of unit resources and also tend to interact more strongly with staff. There is evidence that females might be more proficient with online communication and discussions 
than males. This is certainly the finding of Tsai et al. (2015) where males were not as active as females in online asynchronous discussions. They concluded that female students were more strategic learners by adapting themselves better than the males in these contexts. Whether females' historically socially constructed roles in giving, sharing and responding to others more empathetically is becoming a more discernible point of difference in engagement online and in blended settings, requires more substantial research. While females were seen as more disadvantaged than males at the beginning of modern ICT developments in relation to access and technical skills, this no longer seems the case, and at least some evidence sees the advantage swinging towards females in current technology-enabled environments.

Third, mode of enrolment differences between Located (on-campus) and Cloud (off-campus) students are perhaps unsurprising for those with long histories and experiences of both oncampus and distance education. Traditionally, off-campus students have been mature-aged. In this study, $67 \%$ of responding off-campus students were older than 31 , whereas only $13 \%$ of on-campus students were in this same age group. That is, off-campus students are more settled in personal and professional life and hence, more focused and motivated when returning to study to achieve particular career-related goals. In addition, to strength of focus and motivation, they can demonstrate more developed self-management capabilities. In order to achieve specific objectives, one can see how this cohort might engage more strongly with online teaching opportunities, contacts with staff and be more active in their learning strategies. Well-ordered LMS environments might also facilitate the achievement of their objectives in their relatively time-poor worlds. While not wishing to draw extreme and potentially distorting distinctions, on-campus cohorts can tend to be predominantly schoolleaver, with less well articulated motivations and goal setting around their chosen studies. They may be less focused and, as a consequence, less engaged across-the-board with their online and blended learning experiences. It could also be speculated that on-campus students, as predominantly schooler leaver, or at least younger students, might be more attracted to engage with and through social media away from the institutionally-supported LMS. Hence they might be shifting their engagement from one type of online learning system to another type of social media networking constellation of applications and spaces. These distinctions are now considered in terms of related age group differences in student engagement.

Fourth, the age difference was evident for Active learning, Teaching and Contact with Staff student engagement constructs, with older students more likely to agree with statements made regarding these overarching themes compared to younger students. These findings map closely with differences detected between Located (on-campus) and Cloud (off-campus) cohorts in student engagement. This is understandable given older students tend to be more heavily represented as off-campus enrollees compared to younger students as on-campus enrollees. A point to be made though is that a reasonable proportion of older students do study part-time on-campus. They also might engage more strongly with provided online learning resources and communicative opportunities than younger, on-campus students. Again, irrespective of mode of enrolment, older students might be more highly focused in their motivation to engage with what is provided in online learning environments.

Cohort differences clearly exist. How can they be considered and accommodated? Design and practice still pragmatically revolves around providing online learning space options. A key lynchpin though remains, the general purpose, well-structured and well-regulated LMS environment. What can be highlighted is that well-structured LMS spaces should use 
consistently applied and maintained design interfaces which allow students to easily and effectively access and use key LMS learning resources, assessment and discussion functions. Creating and embedding or simply using the standard interface features of the LMS is important to maximize quality student engagement, irrespective of demographic or other background differences. However, such design interfaces, simple or more sophisticated, must be maintained to a high level of integrity over time and this requires teaching staff to be properly trained and supported in their consistent use. Student engagement can be maximized when consistent interface design is implemented across full courses of study. Breakdowns on the effective set-up and use of design interfaces in LMSs can have a deleterious effect on patterns of student engagement. The application of universal design principles is important in the LMS domain to promote quality online student engagement across the board. Other environments may to a greater or lesser extent, be integrated with the LMS. At this point, the evidence suggests it would be unwise to discount such environments, as for example, this might be jarring and confronting to the international student experience. Teachers need to appreciate alternative social media platforms for student engagement, and the ways different cohorts might engage differently with commonly set up online sites in an LMS. Catering for all and drawing in students constructively to what is provided for most, remains the ongoing design and practice challenge for all online educators. Moreover, it needs to be recognized that there are limits to engaging students in online spaces, and that blended learning approaches need to see face-to-face, in-person spaces specifically designed for complementary interactions between teachers and students which foreground student differences.

\section{Future developments}

The research will progressively investigate the effects of design interventions on student engagement on particular subjects offered at different points of time over the research project period. The research will also report on more generalised blended learning design and practice activities which contribute to higher student engagement irrespective of the discipline, year of offer, and subject-based designs and practices in the business education domains. While generic designs and practices will be developed, particular attention will also be given to further investigating significant identified differences in student engagement based on demographic and background factors. Clearly, a one-size-fits-all approach cannot necessarily meet the needs of such large and diverse student audiences (see Armatas, Holt, \& Rice, 2003).

The issues identified here also lend themselves to further exploration through interpretive qualitative research. Such research methodologies would lead to further explanations as to why the differences identified exist and what the implications might be for enhanced online design and practice. Further meta-analysis is currently being conducted to validate the online student constructs used in the survey. This should help confirm and refine the survey's relevance in investigating key dimensions of student engagement in online and blended learning settings. The study of online blended learning can be further extended into wholly online learning environments, which are now prevalent in global distance education. The survey study has now been adopted to investigate patterns of student engagement in purely online learning and further applications should prove illuminating.

\section{Conclusion}

Multi-modal, multi-campus, diverse audience blended learning designs and practices is a hallmark of Australian higher education in the realm of business education. These types of 
blended learning environments raise pressing challenges in providing all students, irrespective of location, mode of delivery, background and motivation, with the best possible opportunity of mastering unit and course-wide learning outcomes. Assuring the mastery of desired learning outcomes is now central to university strategic curriculum design and course enhancement efforts. It is also a growing imperative in meeting external regulatory and professional accreditation requirements. Designing for student engagement provides a theoretically and conceptually grounded approach to enhancing and assuring student learning. The study has trialed the use of an online student engagement survey over two offerings of the same subject, with a dual focus on online and located/campus-based learning experiences, and the relationship between the two. While few significant differences were identified in overall student engagement over the two periods of offering of the subject, on further analysis interesting differences in the nature of student engagement were found relating to gender, international/domestic students, Located (on-campus)/Cloud (off-campus) students and older (matured aged) and younger (school leaver) students. Reasons for the identified differences have been explored. More and different styles of research should be used to further examine causes of difference in student engagement based on these key demographic and background factors. The balancing act still remains the development of online environments that cater for the needs of students who rely almost entirely on them to achieve the required learning outcomes, and those who best benefit from dual engagement with both online and located/campus learning opportunities for learning achievement. Paramount is the need to understand the diversity in the student population and that different student cohorts may engage in different ways with blended learning designs.

One of the most significant findings for institutions strategically committed to blended and online learning is the continued importance of substantial investment in online learning systems, which can best enable the variety of designs and practices required to accommodate different student needs, backgrounds and circumstances. Major investments in one centrally controlled institutional system, as the core online learning interface and platform, for an institution's student population seems vindicated through the results of this study. The ubiquitous LMS platform now well entrenched in most universities' technological infrastructure seems like it has and will continue to meet the test of time.

\section{References}

Armatas, Holt, D. \& Rice, M. (2003). Impacts of an Online-Supported, Resource-Based Learning Environment: Does One Size Fit All? Distance Education, 24(2), 141-158. DOI: $10.1080 / 0158791032000127446$

Astin, A.W. (1985). Achieving Educational Excellence: A Critical Analysis of Priorities and Practices in Higher Education. San Francisco, CA: Jossey-Bass.

Bennett, S., Dawson, P., Bearman, M., Molloy, E., \& Boud, D. (2017). How technology shapes assessment design: Findings from a study of university teachers. British Journal of Educational Technology, 48(2), 672-682. DOI: 10.1111/bjet.12439

Bonk, C.J. \& Zhang, K. (2008). Empowering online learning: 100 + activities for reading, reflecting, displaying, $\mathcal{E}$ doing. San Francisco: John Wiley \& Sons.

Boud, D. (2010). Student Assessment for Learning In and After Courses. Final Report for Senior Fellowship. Australian Learning and Teaching Council (ALTC): 
http://www.olt.gov.au/resource-student-assessment-learning-and-after-courses-uts2010

Boud, D. \& Molloy, E. (2013). (Eds.). Feedback in Higher and Professional Education Understanding it and doing it well. London: Routledge.

Challis, D., Holt, D.M. \& Rice, M. (2005), 'Staff perceptions of the role of technology in experiential learning: A case study from an Australian university', Australasian Journal of Educational Technology, 21(1), 19-39.

Chen, R. T-H., Bennett, S. \& Maton, K. (2008). The adaptation of Chinese international students to online flexible learning: two case studies. Distance Education, 29(3), 307-323. DOI: $10.1080 / 01587910802395821$

Chen, S.J., Hsu, C.L. \& Caropreso, E.J. (2006). Cross-cultural collaborative online learning: When the West meets the East. International Journal of Technology in Teaching and Learning, 2(1), 17-35.

Chickering, A.W. \& Gamson, Z.F. (1987). Seven principles for good practice in undergraduate education. AAHE Bulletin, 39(7), pp. 3-7.

Choi, S. H.-J. \& Nieminen, T.A. (2013). Factors influencing the higher education of international students from Confucian East Asia. Higher Education Research $\mathcal{E}$ Development, 32(2), 161-173. DOI: 10.1080/07294360.2012.673165

Coates, H. (2006). Student engagement in campus-based and online education: university connections. Routledge: London.

Coates, H. \& McCormick, A.C. (Eds.) (2014). Engaging University Students International Insights from System-Wide Studies. Springer: Singapore.

Coates, H. \& McCormick, A.C. (2014). Introduction: Student Engagement - A Window into Undergraduate Education. In H. Coates \& A.C. McCormick (Eds.) (2014). Engaging University Students International Insights from System-Wide Studies. Springer: Singapore, pp.1-12.

Dawson, P. (2017). Assessment rubrics: towards clearer and more replicable design, research and practice. Assessment \& Evaluation in Higher Education, 42(3), 347-360. DOI: 10.1080/02602938.2015.1111294

Garrison, D.R. \& Anderson, T. (2003). E-Learning in the 21 $1^{\text {st }}$ Century. A Framework for Research and Practice. London: Routledge Falmer.

Gunn, C., French, S., McLeod, H., McSporran, M. \& Conole, G. (2002). Gender issues in computer-supported learning. Research in Learning Technology, 10(1), 32-44.

Hagel, P., Carr, R. \& Devlin, M. (2012). Conceptualising and measuring student engagement through the Australasian Survey of Student Engagement (AUSSE): a critique. Assessment E Evaluation in Higher Education, 37 (4), 475-486. DOI: 10.1080/02602938.2010.545870

Henderson, M., Boud, D., Molloy, E., Dawson, P., Phillips, M., Ryan, T., Walker, H. \& Mahoney, P. (2016). Feedback for learning Closing the assessment loop. Federal Australian Government Office for Learning and Teaching (in progress). Project website: http://newmediaresearch.educ.monash.edu.au/feedback/ 
Hofstede, G. (2001). Culture's Consequences: comparing values, behaviors, institutions, and organizations across nations (2nd Ed.). Thousand Oaks, CA: SAGE Publications.

Holt, D.M. \& Challis, D. (2007). From policy to practice: one university's experience of implementing strategic change through wholly online teaching and learning, Australasian Journal of Educational Technology, 23(1), 110-131.

Holt, D., Segrave, S. \& Cybulski, J. (2011) (Eds.) Professional Education Using E-Simulations: Benefits of Blended Learning Design. Hershey, US: IGI Global.

Howson, C.K. \& Buckley, A. (2017). Development of the UK engagement survey. Assessment $\mathcal{E}$ Evaluation in Higher Education, 42(7), 1132-1144. DOI: 10.1080/02602938.2016.1235134

Jonsson, A. (2014). Rubrics as a way of providing transparency in assessment. Assessment $\mathcal{E}$ Evaluation in Higher Education, 39(7), 840-852. DOI: 10.1080/02602938.2013.875117

Kopcha, T.J., Schmidt, M.M. \& McKenney, S. (2015). Editorial: Special issue on educational design research (EDR) in post-secondary learning environments. Australasian Journal of Educational Technology, 31(5), i-ix.

Kuh, G.D. (2003). What we're learning about student engagement from NSSE. Change, 35(2), 24-31.

Kuh, G.D., Kinzie, J., Schuh, J.H., Whitt, E.J., \& Associates (2005). Student success in college: Creating conditions that matter. San Francisco: Jossey-Bass.

Lau, W.W.F \& Yuen, K.H.A. (2010). Gender differences in learning styles: Nurturing a gender and style sensitive computer science classroom. Australasian Journal of Educational Technology, 26(7), 1090-1103.

Lawson, R. (2015). Curriculum design for assuring learning - leading the way. Final Report for Senior Fellowship. Office for Learning and Teaching (OLT): http://www.olt.gov.au/resource-curriculum-design-assuring-learning-leading-way2015

Li, Q. (2005). Gender and CMC: A review on conflict and harassment. Australasian Journal of Educational Technology, 21(3), 382-406.

Liu, X., Liu, S., Lee, S.-h \& Magjuka, R.J. (2010). Cultural Differences in Online Learning: International Student Perceptions. Educational Technology \& Society, 13(3), 177-188.

Markauskaite, L. (2006). Gender issues in preservice teachers' training: ICT literacy and online learning. Australasian Journal of Educational Technology, 22(1), 1-20.

McKenney, S.E. \& Reeves, T.C. (2012). Conducting educational design research. New York: Routledge.

McSporran, M. \& Young, S. (2001). Does gender matter in online learning? Research in Learning Technology, 9(2), 3-15.

Nicol (2010). Re-engineering Assessment Practices in Higher Education: http://www.reap.ac.uk/Home.aspx

Oliver, B. (2013). Graduate attributes as a focus for institution-wide curriculum renewal: innovations and challenges. Higher Education Research \& Development, 32(3):450-63. 
Pace, C.R. (1979). Measuring Outcomes of College: Fifty Years of Findings and Recommendations for the Future. San Francisco, CA: Jossey Bass.

Pace, C.R. (1995). From Good Practices to Good Products: Relating Good Practices in Undergraduate Education to Student Achievement. Paper presented at the Association for Institutional Research, Boston.

Palmer, S. \& Holt, D. (2014). Development of student and academic staff perceptions of the elements of an online learning environment over time. Australasian Journal of Educational Technology, 30(4), 375-89.

Parkin, H.J., Hepplestone, S., Holden, G., Irwin, B. \& Thorpe, L. (2012). A role for technology in enhancing students' engagement with feedback. Assessment $\mathcal{E}$ Evaluation in Higher Education, 37(8), 963-973. DOI: 10.1080/02602938.2011.592934

Pye, G., Holt, D., Salzman, S., Bellucci, E. \& Lombardi, L. (2015). Engaging diverse student audiences in contemporary blended learning environments in Australian higher business education: Implications for design and practice. Australasian Journal of Information Systems, 19, 1-20.

Reeves, T.C. (2015). Educational design research: Signs of progress. Australasian Journal of Educational Technology, 31(5), 613-20.

Salmon, G. (2011). E-moderating. The Key to Teaching and Learning Online. New York: Routledge.

Small, F. \& Attree, K. (2016). Undergraduate student responses to feedback: expectations and experiences, Studies in Higher Education, 41(11), 2078-2094. DOI: 10.1080/03075079.2015.1007944

Teo, T., Fan, X. \& Du, J. (2015). Technology acceptance among pre-service teachers: Does gender matter? Australasian Journal of Educational Technology, 31(3), 235-251.

Tinto, V. (1993). Leaving College: Rethinking the Causes and Cures of Student Attrition. Chicago, IL: University of Chicago Press.

Tinto, V. (1997). Classrooms as communities: exploring the educational character of student persistence. Journal of Higher Education, 68(6), pp.599-623.

Tsai, M.J., Liang, J-C., Hou, H-T. \& Tsai, C-C. (2015). Males are not as active as females in online discussion: Gender differences in face-to-face and online discussion strategies. Australasian Journal of Educational Technology, 31(3), 263-77.

Wallace, P. (1999). The Psychology of the Internet. New York: Cambridge University Press.

Winstone, N.E., Nash, R.A., Rowntree, J. \& Parker, M. (2017). 'It'd be useful, but I wouldn't use it': barriers to university students' feedback seeking and recipience. Studies in Higher Education, 42(11), 2026-2041. DOI: 10.1080?03075079.2015.1130032

Wong, K-T., Teo, T. \& Russo, S. (2012). Influence of gender and computer teaching efficacy on computer acceptance among Malaysian student teachers: An extended technology acceptance model. Australasian Journal of Educational Technology, 28(7), 1190-1207.

Zhang, J. (2007). A cultural look at information and communication technologies in Eastern education. Education Technology, Research and Development, 55(3), 301-314. 


\section{Appendix:}

Online student engagement constructs for contemporary blended learning environments

\section{Online Active Learning}

- $\quad$ I used online materials to improve my learning

- $\quad$ I used online materials to make classroom learning more meaningful

- I identified expected work standards using the CloudDeakin (LMS) unit site

- I found that online materials challenged me to learn

\section{Online Social Interaction}

- $\quad$ Teaching staff participated in online discussions

- I found it easy to explain my ideas in online discussions

- I had helpful online discussions with other students

- $\quad$ I met new people when using CloudDeakin (LMS)

\section{Online Collaboration}

- $\quad$ I used CloudDeakin (LMS) with other students around campus (on-campus students only)

- $\quad$ I used CloudDeakin (LMS) to do academic work with other students

- $\quad$ I used CloudDeakin (LMS) to work with other students outside of class (on-campus students only)

- $\quad$ I used CloudDeakin (LMS) to communicate with other students

\section{Online Teaching}

- $\quad$ Staff used CloudDeakin (LMS) to clarify what was required to do well

- $\quad$ Staff used CloudDeakin (LMS) in ways that improved the overall teaching

- Academic staff made an effort to communicate with students online

- $\quad$ Staff used CloudDeakin (LMS) to provide students with extra assistance

- $\quad$ Teaching staff used CloudDeakin (LMS) to tailor activities for students

- $\quad$ Teaching staff used CloudDeakin (LMS) to discuss interesting issues

\section{Online Assessment}

- Assignments were easy to locate online

- $\quad$ Tests were easy to undertake online

- Assignments were easy to submit online

- $\quad$ Online assignment submission gave me more time to complete assessable work

- $\quad$ Online assignment feedback helped me improve my understanding of the topic

- $\quad$ Online assignment feedback helped me prepare for subsequent assessable work 


\section{Online Academic Relevance}

- $\quad$ Using CloudDeakin (LMS) made my studying seem more relevant

- $\quad$ Using CloudDeakin (LMS) made me feel part of the University

- $\quad$ Using online materials helped me put my study in real-world contexts

\section{Online Contact with Staff}

- $\quad$ I used CloudDeakin (LMS) to contact academic staff

- I found it easy to communicate with staff online

- I had individual contact with academic staff online

Copyright: @ 2018 Pye, Holt \& Salzman. This is an open-access article distributed under the terms of the Creative Commons Attribution-NonCommercial 3.0 Australia License, which permits non-commercial use, distribution, and reproduction in any medium, provided the original author and AJIS are credited.

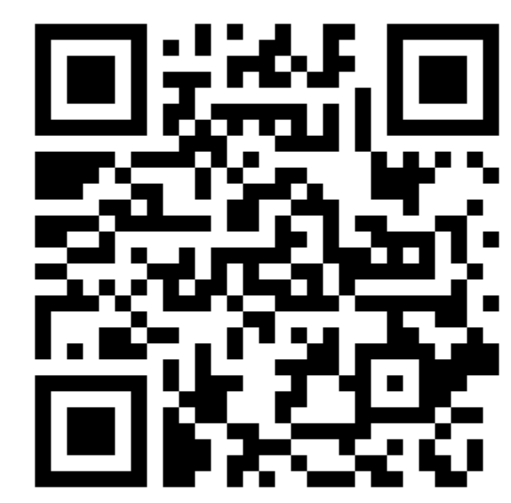

